\title{
Interactive comment on "Erosion risk assessment and identification of susceptibility lands using the ICONA model and RS and GIS techniques" by Hossein Esmaeili Gholzom et al.
}

\section{Hossein Esmaeili Gholzom et al.}

abmoeini@yahoo.com

Received and published: 17 August 2020

dear referee. Thank you very much for your efforts. We hereby kindly appreciate your careful scrutiny on our submitted manuscript. It was tried to get your satisfaction by improving the manuscript. The following answers are offered to convince the respectful referees. We request you inform us if any further correction will be needed. I have marked the corrected items in red colour in the article.

Printer-friendly version

Discussion paper

Best regards Dr. moeini,

General remarks This is a rather confusing manuscript for several reasons. The most 
important issue is the language. I advise the authors strongly to use a professional, native English translator for improving the language. Furthermore, the objective of this study is not clearly described. In the end, the erosion risk assessment using the ICONA model is compared with an existing result from the PSIAC model, without a discussion on the comparison. This article was revised by a native and professional English translator.

Interactive

comment

The purpose of this paper is to apply the ICONA model and using the GIS and RS techniques to assess the potential for erosion risk in a watershed in northern Iran and the southern part of the Alborz Mountains. To confirm the results of the ICONA model, while obtaining data and information from the basin by remote sensing, frequent visits to the basin and identifying the types of erosion and sensitive areas, the PSIAC model (as the base model) was used simultaneously. Finally, we matched the results of the ICONA model with the observations and data in the field and the results of the PSIAC model. The results of PSIAC model and ICONA qualitative model were highly consistent with field observations.

In 3.3, it is stated that high erosion intensity is not observed in the study area (line 277) (not clear where this is coming from), but no discussion on this outcome is made for discussing the results from the ICONA model. I regret to state that this manuscript is unacceptable. Yes, the Referee is right and this sentence (and high erosion intensity states are not observed in the study area) is added in line 277 and we removed it from the article.

If the authors present this in a C1 NHESSD Interactive comment Printer-friendly version Discussion paper better way, indicating clearly the objectives, describe the validation of the results, put the results in perspective and discuss the consequences of the outcome in terms of possible focus areas for soil conservation, this may become an acceptable manuscript. Specific remarks: 1. Line 31: present and describe the different models. You have listed here just a sequence of models without categorizing them in e.g. empirical versus process based, different timescales (event based, annual), dif-

Printer-friendly version

Discussion paper 
ferent spatial scale. In the introduction, while correcting, we have provided information about the models (lines 30 to 37 and lines 40 to 45 and lines 68 to 71).

2. Add more literature on erosion models and erosion risk assessment studies. As stated in Section 1. From lines 30 to 37 , lines 40 to 45 and lines 68 to 71 more information was added about the models.

3. Line 38: why is it necessary to find 'quick and timely solutions'? According to the findings of Mohammadi, 2018 (line 26) and Naderi, 2011 ( line 29) of the soil erosion situation in Iran and the lack of sufficient data in most watersheds, it is necessary to find quick and timely solutions to assess the erosion situation. The ICONA model uses GIS and RS to perform erosion assessment in the watershed in less time and in a timely manner. This is continued in lines 50 and 51 .

4. The introduction contains a lot of redundancies, try to funnel a bit more starting from the broad description of erosion models, risk assessment, the study site situation, and your objectives in this. According to the referee, red content has been added in introduction (lines 30 to 37 , lines 40 to 45 , lines 68 to 71 and lines 72 to 82 ).

5. Section 2.1: I miss data of the climate for the study area. Some of the climate content of the study area was not mentioned, which is mentioned in section 1-2 and in line number 90 and 91 ).

6. Section 2.2: this sounds like a lot of work done for gathering the input data, but nowhere are results or a discussion of this procedure presented. Only the final map is presented. Yes, a lot of work has been done to collect input data. But a lot of the research data will be in the supplement and data availability section on line 374 and in the blog created.

7. Line 104: so you validate your model result with outcome of another model? That is no guarantee that results are reliable. Yes, you are right. As explained in the first part and section 15, the purpose of this sentence is to assessments the results of

Printer-friendly version

Discussion paper 
the ICONA qualitative model compared to the PSIAC numerical model. However, the results of these models were matched with multiple field visits and erosion status assessments. That's why we delete the word credit.

8. Table 1: Caption does not explain what is in the Table, what is MB, M, B, a, b, c etc.? The description of these letters is given at the bottom of Table 1. Lines 181 to 187.

9. Table 3: what is K-factor? K-factor, shows the degree of soil erodibility in Table 3.

10. Legend Fig 3: 'Very low' is lower than 'Low', so sequence should be adapted. Swap colours for 'Steep' and Very steep' (red is normally worse than light red) We have changed the colors and legend map 3 .

11. Line 201-202: this procedure should be explained in 'methodology', and a discussion on the outcome should be presented. What do these figures imply? The contents of lines 201 and 202 are given in sections 2-2 and in lines 114 to 117 . We have removed Table 5 and given the necessary numbers.

12. Fig. 6: Colours and legend seem to be mixed here, use the same colours as for Fig 3.

We have changed the colors and legend map 6 .

13. Fig 7b: Legend is not in sequence of severity ('low-moderate-very low', should be 'very low-low-moderate'?

We have changed the colors and legend map $7 \mathrm{~b}$.

14. Line 315: what is 'human erosion'? This term was modified in line 315, (Lines 319 and 320).

15. Line 353: where is the conclusion that the erosion risk map is 'sufficiently accurate' based on? There is no ground prove (measured data) for this presented. If it is based on the comparison between models, then I would have expected a better discussion on that, and the limitations of this procedure explained. We added these section in the

Printer-friendly version

Discussion paper 
discussion section.

Numerous erosion forms have been identified through numerous studies and visits to NHESSD the study area. PSIAC model with numerical data of 9 factors affecting erosion, the main purpose is to compare the results, not validation. The PSIAC model has been used (as a base model) in the field. In this study, the results of erosion risk assessment with the ICONA qualitative model are consistent with the map of erosion patterns and severity in the field.

Interactive comment on Nat. Hazards Earth Syst. Sci. Discuss., https://doi.org/10.5194/nhess2020-85, 2020. 